\title{
Environmental assessment of individual and collective manure management systems
}

\author{
Giorgio Provolo, Aldo Calcante, Francesca Perazzolo, Alberto Finzi, Filippo Volontè, \\ Davide Grimaldi, Mauro Pinnetti, Giorgia Cocolo, Ezio Naldi, Giorgio Galassi, \\ Elisabetta Riva
}

\author{
Department of Agricultural and Environmental Science, University of Milan, Italy
}

\begin{abstract}
In intensive livestock area with large nutrient surplus collective management systems can be a suitable solution. However, the collective system should carefully evaluated for environmental sustainability to avoid cross effects. The aim of this study was to evaluate the environmental effects of the introduction of a collective treatment plant for energy production and nitrogen removal. For this purpose an assessment methodology, for individual farms and collective treatments plants, has been defined to estimate the emissions of the main pollutants to the air $\left(\mathrm{CO}_{2}, \mathrm{CH}_{4}, \mathrm{~N}_{2} \mathrm{O}, \mathrm{NH}_{3}\right)$ and to the soil $(\mathrm{N})$. The method devised has been assessed in a case study (a treatment plant collecting manure from 12 farms). The main effect of the introduction of the collective management system from the environmental point of view is a reduction of greenhouse gases emissions of $61 \%$ due to methane emission reduction and renewable energy production. Furthermore, it reduces the amount of nitrogen to be applied to land from $430 \mathrm{~kg} \mathrm{ha}^{-1}$ to about $220 \mathrm{~kg} \mathrm{ha}^{-1}$, decreases the emission of ammonia in the air by about $17 \%$ due to lower amount of nitrogen that is managed by farms in the storage and spreading operations.
\end{abstract}

\section{Introduction}

The environmental impact related to intensive livestock farming is often determined by manure management systems that do not use best available techniques. Furthermore, in areas with a high density of ani-

Correspondence: Giorgio Provolo, Department of Agricultural and Environmental Science, University of Milan, via Celoria 2, 20133 Milano (Italy) Tel.+39.02.5031 6855. E-mail: giorgio.provolo@unimi.it

Key words: nutrient surplus, treatment plant, anaerobic digestion, nitrogen removal.

Acknowledgments: this research was financially supported by the MANEV project No. LIFE09 ENV/ES/000453.

(C) Copyright G. Provolo et al., 2013

Licensee PAGEPress, Italy

Journal of Agricultural Engineering 2013; XLIV(s2):e36

doi:10.4081/jae.2013.s2.e36

This article is distributed under the terms of the Creative Commons Attribution Noncommercial License (by-nc 3.0) which permits any noncommercial use, distribution, and reproduction in any medium, provided the original author(s) and source are credited. mals, the load of nutrients exceed crop requirements, causing a relevant environmental problem. As livestock intensification continues, there is a need for development of technology and strategies to control the associated environmental problems (Petersen et al., 2007).

In this framework and considering the regulatory constraints (Community directives 91/676/EEC and 2010/75/EU), the application of different techniques of collective treatment and management of manure, represents a possible solution to the sustainability of livestock farms.

A manure management system needs to address the principal local environmental risks and any excess of nutrient over the requirements of the local crop production, since manure disposal will often be (either directly or indirectly) by land application. Good strategies enable a targeted application of nutrients that meets, but does not exceed local crop needs. Criteria for the design of the future waste management systems and the improvement of existing ones include the maximization of nutrient recycling and of social acceptance, the protection of air, soil and water resources, human health and safety, the control of manure application rates, and the minimization of capital and operating costs and energy requirements (Lagüe et al., 2005). The present concern about global climate change should stimulate practical solutions in areas with nutrient surplus towards a contribution of the manure management to an effective reduction of greenhouse gases (GHGs). The implementation of some technologies and practices can mitigate the impact of agriculture on Climate Change (IPCC, 2006). At the same time such solutions must also bring a reduction in other emissions to air (especially ammonia), as well as further environmental protection for water and soil. In order to control nutrient surpluses and other risks, environmental technologies and management strategies are needed. Unfortunately, the development is impeded by the lack of well-defined market conditions. Economic and market policies and regulations of manure management present boundary conditions which determine if a given technology is attractive to the farmer. Moreover a gap between the development in scientific understanding of the multiple risks of manure management and the take-up of this knowledge by policy makers still exists, it is now understood that cost-effective solutions can only be found in integrated policies (Petersen et al., 2007).

Therefore, integrated assessment tools and decision support systems are now required which have yet to be developed. The regulation aiming to minimise the environmental impact of livestock manure becomes one of the many external constraints that farmers - and these assessment tools - have to consider. When dealing with livestock manures in a whole-farm perspective, the evaluation of cross- and side-effects of regulations based on scientific knowledge still poses significant challenges. For this reason collective systems might be an interesting solution but it should carefully evaluated for environmental sustainability to avoid cross effects and the increase of emissions to air. The main emissions to air from farms are: methane $\left(\mathrm{CH}_{4}\right)$ produced by ruminal digestion and stored manure, ammonia $\left(\mathrm{NH}_{3}\right)$ and 
carbon dioxide $\left(\mathrm{CO}_{2}\right)$ as a result of animal respiration and manure stored. Finally, during the spreading phase produces losses of $\mathrm{NH}_{3}$ volatilization and nitrous oxide $\left(\mathrm{N}_{2} \mathrm{O}\right) . \mathrm{NH}_{3}$ causes acidification of soil and water. Approximately, $90 \%$ of $\mathrm{NH}_{3}$ emissions are due to agriculture in several European countries, $40 \%$ of which coming from animal housing and manure storage (Rigolot et al., 2010). $\mathrm{CO}_{2}$ emissions in agriculture is negligible because it is derived mainly from burning fossil fuels. The amounts of $\mathrm{CH}_{4}$ and $\mathrm{N}_{2} \mathrm{O}$ emitted to the atmosphere are low compared to $\mathrm{CO}_{2}$, but their global warming potentials are, respectively, 21 and 310 times higher than that of $\mathrm{CO}_{2}$. Within the European Union, agriculture has been estimated to contribute $49 \%$ of anthropogenic $\mathrm{CH}_{4}$ emissions and $63 \%$ of $\mathrm{N}_{2} \mathrm{O}$ emissions (Sommer et al., 2004). The extreme involvement of agriculture and livestock farming on environmental issues, involves using computer models to estimate the pollutants emissions of during farm activities. These models can be used both to highlight the criticality of the farms and to establish sustainable manure management systems (Burton and Turner, 2003).

Therefore, when a new treatment facilities is introduced, the reduction of GHGs and ammonia emissions has to be assessed together with the nutrient load on the land receiving the treated manure.

This study has been developed in the framework of the LIFE+ 2009 "Evaluation of manure management and treatment technology for environmental protection and sustainable livestock farming in Europe (MANEV)" project (http://www.lifemanev.eu/). MANEV is an European project of large-scale demonstration framed within the LIFE + Programme of Environment Policy and Governance, whose main objective is to improve environmental protection and sustainability of livestock promoting the use of treatment technologies in different saturated or surplus areas in the production of livestock manure across Europe. Eight partners will assess 13 treatment technologies and manure management systems, located in eight regions with high pig production belonging to four European countries, following a common monitoring and assessment protocol that has been developed in the project. The results of each assessment could be referred to $\mathrm{CO}_{2}$ equivalent units in order to assess its contribution to fight against climate change.

A software tool will be developed based on the results and all the information and data obtained from the technology assessments developed in the project, which is intended to provide an objective decision support tool to determine the most appropriate treatment according to the local circumstances, without being these mere technological comparison but taking into account aspects like for example environment, society, economics, local regulation,... of every case study. Europe will be endowed with a common decision support tool to the various technologies beneficial for both farming sector (search for the optimal technology) and the administration (environmental control and promotion of the use of technologies).

The activity carried out in the project include the definition of a common protocol to assess the emissions of the different treatment systems studied within the project.

The aim of this study was to evaluate the environmental effects of the introduction of a collective treatment plant for energy production and nitrogen removal. For this purpose the assessment methodology defined in the MANEV project, for individual farms and collective treatments plants, has been adopted to estimate the emissions of the main pollutants to the air $\left(\mathrm{CO}_{2}, \mathrm{CH}_{4}, \mathrm{~N}_{2} \mathrm{O}, \mathrm{NH}_{3}\right)$ and to the soil (N). The method devised has been assessed in a case study (a treatment plant collecting manure from 12 farms).

\section{Materials and methods}

\section{The monitored plant}

The studied management system is a collective treatment plant with an anaerobic digestion phase for energy production and a nitrogen removal phase. It is located in northern Italy, Bergamo province, in an intensive livestock area where there is a high surplus of nitrogen and has been designated as vulnerable zone.

The treatment plant involves 12 livestock farms (mainly pigs, but also cows and poultry), located 0.5 to $6 \mathrm{~km}$ far away from the plant, for a total daily production of around $220 \mathrm{~m}^{3}$ of manure (Table 1). The manure is transported by slurry tankers with the exception of the nearby farm, connected by mean of a pipeline. At first, manure is processed in an anaerobic digestion reactor for the production of energy. This step consists of two digesters, with a volume of $2280 \mathrm{~m}^{3}$, and a postdigester (of $3185 \mathrm{~m}^{3}$ volume). One of the two digesters is fed with manure and other biomasses (silage) around $10 \mathrm{t}$ per day, while the second one is fed with raw manure. The digestate is then conveyed to the post digester. The digested effluent is then separated, in order to reduce load and to separate most of the phosphorus. The solid-liquid separation treatment is performed by two screw press separators. The solid fraction is sold, while the liquid fraction is treated for biological nitrogen removal. This process is carried out by two Sequencing Batch

Table 1. Main characteristics of the farms of the collective management system examined.

\begin{tabular}{|c|c|c|c|c|}
\hline Farm & Type of livestock & Number of heads & Total live weight ( $t$ ) & Total N (kg) \\
\hline $\mathrm{Al}$ & dairy cows & 640 & 204 & 26628 \\
\hline A2 & dairy cows & 560 & 175 & 22049 \\
\hline A3 & dairy cows & 790 & 246 & 30833 \\
\hline A4 & hens & 70000 & 70 & 16100 \\
\hline A5 & dairy cows & 322 & 100 & 12636 \\
\hline A6 & dairy cows & 999 & 333 & 43955 \\
\hline A7 & beef cattle & 80 & 25 & 2134 \\
\hline A8 & dairy cows & 527 & 164 & 20639 \\
\hline A9 & fattening pigs & 1400 & 102 & 11154 \\
\hline $\mathrm{A} 10$ & fattening pigs & 3500 & 271 & 29684 \\
\hline $\mathrm{A} 11$ & fattening pigs & 1800 & 142 & 15583 \\
\hline $\mathrm{A} 12$ & dairy cows & 1190 & 371 & 46900 \\
\hline
\end{tabular}


Reactors (SBRs), having a capacity of $660 \mathrm{~m}^{3}$ each, which operate in parallel. The cycles consist of four steps: feed (15-20 $\mathrm{m}^{3}$ in 20 minutes), mixing (90 minutes), aeration (230 minutes) and settling (20 minutes).

The effluent is finally stored in three storage tanks. Then, it is transported to the farms by slurry tankers or pipelines.

\section{Methodology used}

The assessment protocol developed include the following four different steps:

- Step 1. Farm storage: This step would assess the impact of storage tank period inside the farm and its consequences in its subsequent treatment.

- Step 2. Transport and intermediate storage: This step would assess the impact of the transport of raw manure or to an intermediate storage of the treatment plant.

- Step 3. Treatment: the treatment plant has been monitored in order to provide a complete assessment of the treatment and its main process units. Moreover, raw manure and other materials fed to the process has been be characterized so as to the end-products of the process.

- Step 4. End-products management: End-products has been characterized and its transport and storage has been assessed with methodologies specified for steps 1 and 2. Same methodologies will be used for land spreading.

Environmental impact of the construction step was not considered at the moment. Nevertheless, it will be a further improvement by including information according to average European values for different materials and equipment. All the emissions related to the management of cosubstrates or additional material included in the process, before its treatment, has not been assessed within our system. These emissions are considered to belong to the system of the process that generates them. Emissions related to the treatment period and up to its final destiny are assessed all together with manure evaluation as part of the treatment technology impact.

\section{Environmental assessment}

The methodology used for the calculation of the emissions was applied for each pollutant and for each step of the manure management (De Vries and de Boer, 2010).

$\mathrm{CO}_{2}$ emission are not considered for farm storage. For transport the Tier 2 methodology of IPCC 2006 has been used. Emissions were estimated from the fuel consumed and the distance travelled. In general, the fuel consumed is appropriate for $\mathrm{CO}_{2}$ and the distance travelled by vehicle type and road type is appropriate for $\mathrm{CH}_{4}$ and $\mathrm{N}_{2} \mathrm{O}$ (IPCC, 2006). The average values of fuel consumption per distance unit travelled by the vehicles has been obtained by direct measurement during the monitoring period. The $\mathrm{CO}_{2}$ emission value has been obtained using as emission factor the carbon content of the fuel multiplied by 44/12.

Energy balance in the treatment plant (expressed as $\mathrm{CO}_{2}$ ) has been obtained by the difference of energy produced and the energy required to run the treatment. Data derives from plant monitoring.

The estimate of $\mathrm{CH}_{4}$ and $\mathrm{N}_{2} \mathrm{O}$ emissions has been obtained by using IPCC 2006 (Tier 2) methodology. For this purpose, the information has been obtained from the characterization of manure (Total nitrogen, volatile solids, etc.). For the other factors of this methodology, the default values has been used.

This method has been used for: Farm storages, intermediate farm storages, off-road transportation. The methane emissions during treat- ment have been obtained from literature values for similar treatments. In the biogas production emissions has been considered 5\% (leackage) and in the SBR treatment $10 \%$ of the potential value (Loyon, 2006; Hansen, 2006; Brown, 2008).

For emissions related to land application the farm practice has been obtained from the recordkeeping of the farms.

Ammonia emission takes place in all those activities in which pig manure is in contact with air (storage, land application and tanks without cover in treatment plants) and transport activities.

When calculating emissions of NH3 using a mass flow approach, a system based on Total ammoniacal nitrogen (TAN) is preferred to one based on total N, as is used by IPCC to estimate emissions of N20 (EMEP/EEA, 2009).

EMEP/EEA 2009 Tier 2 methodology has been used to calculate ammonia emissions from the manure management.

To evaluate emissions from farm and intermediate storage, data of the different type of pits available in each farm has been collected. As the storage period (Hydraulic retention time) is limited when the manure is transported to the treatment plant, a duration factor has been introduced to avoid overestimation of the emissions. For this reason a linear trend of emissions has been considered and the default emission factor has been reduced according the ratio between the actual duration and a duration of 180 days.

Ammonia emissions during treatment has been obtained by literature. For the final storage the same EMEP/EEA 2009 Tier 2 methodology has been used but the TAN content was calculated according to the transformation in the treatment plant. To evaluate emissions during distribution the average conditions, derived from farm recordings was used in order to obtain an average emission factors.

To assess the water pollution risk, the crop balance method has been used. A modeling approach to nitrogen leaching and to nutrients in runoff was outside the scope of this work and the information required for this evaluation was not readily available (including soil analyses). The crop requirements were obtained by the farm records, using the average yields and nutrient content of the products according to the local data.

For the treatment plant the removal efficiencies were obtained from the monitoring data. The following values were used:

- Volume=1,01 (consider the addition of biomass and the solid manure produced in separation step)

- Total solids $=0,46$ (consider the reduction in the anaerobic digestion, the separation and the biological treatment)

- Volatile solids $=0,35$ (consider the reduction in the anaerobic digestion, the separation and the biological treatment)

- Total nitrogen= 0,55 (consider the addition of nitrogen with the biomass, ammonia emissions and the nitrogen removal in the biological treatment)

- Ammoniacal nitrogen=0,46 (consider also the mineralization of the organic nitrogen)

The emissions factors from the treatment plant, according the methodology explained resulted as follows:

- Emission of $\mathrm{NH}_{3}=7,59 \%$ of total nitrogen

- Emission of $\mathrm{N}_{2} \mathrm{O}=2,17 \%$ of total nitrogen

- Emission of $\mathrm{CH}_{4}=179,1 \mathrm{~m}^{3}$ (t Volatile Solids input) ${ }^{-1}$

- Emission of $\mathrm{CO}_{2}=-458,71 \mathrm{~kg} \mathrm{CO}$ ( $\mathrm{t}$ Volatile Solids input)-1

The methodology reported has been applied to two different scenarios:

- Scenario 1: all the farm act individually and spread the produced manure in their fields

- Scenario 2: all the manure produced in individual farms is transported to the collective treatment plant and, after treatment, is transported back to each farm that provides to store it and to land spreading according to the manure management plan. 


\section{Results}

The evaluation of the emissions related to each livestock is summarized in Table 2. It should be noticed that for the scenario 2, the results are reported for each livestock also if a collective treatment plant is adopted, in order to better compare the two scenarios.

The average reduction of ammonia emissions resulted of $17 \%$. This value might be considered low compared to the nitrogen removal efficiency of the treatment plant (55\%). However it should be considered that the emissions from the buildings are not affected and that the nitrogen remaining in the final product is mineralized thus the emissions during storage and spreading are higher.

The effect of the collective management system on ammonia emissions varies among livestock farms (Figure 1). This variation is explained by the different influence of the emissions before the treatment on the total emissions. In fact, the manure removal system and the amount of solid manure affect the ammonia emissions in this step of the management and have a different share of the total ones.

The emissions of GHGs are greatly influenced by the collective treat- ment system (Figure 2). Nitrogen oxide emissions are more than two times higher due to the negative effect of the treatment system. On the other hand, the methane emissions lower a lot (51\%) due to the recovery of the biogas plant. Of course, the methane emissions in the intermediate storage before the transportation to the treatment plant entails some methane emissions (collection is made weekly in each farm) and the end product has still some methane production potential (the volatile solids are $2-2.4 \%$ of the total mass of the slurry applied to the land). However the main methane emissions in the scenario 2 are related to the losses of methane produced, due to leakages. The value used for this purpose ( $5 \%$ of the methane produced) might be overestimate, but there are limited information about losses from the biogas plants and further investigation are needed to have a better assessment.

The additional benefit of the treatment plant refers to the reduction of $\mathrm{CO}_{2}$ emissions due to the energy production. The overall benefit in term of total $\mathrm{CO}_{2}$ eq. reduction is $61 \%$ that seems a very good achievement. Figure 3 shows the comparison of the two scenarios for each farm. The only situation with a limited reduction of GHGs is the farm A4 (egg production) where the manure management in building and

Table 2. Emissions estimated by the two management systems (scenario 1 and 2) for each farm.

\begin{tabular}{|c|c|c|c|c|c|c|c|c|}
\hline farm & $\begin{array}{c}\text { scenario } 1 \\
\mathrm{NH}_{3} \\
\left(\mathrm{~kg} \mathrm{year}^{-1} \text { ) }\right.\end{array}$ & $\begin{array}{c}\text { scenario } 2 \\
\mathrm{~N}_{2} \mathrm{O} \\
\left(\mathrm{kg}^{\text {year }}{ }^{-1}\right)\end{array}$ & $\begin{array}{c}\mathrm{CH}_{4} \\
\text { (kg year-1) }\end{array}$ & $\begin{array}{c}\mathrm{CO}_{2} \\
\left(\mathrm{~kg} \mathrm{year}^{-1}\right)\end{array}$ & $\begin{array}{c}\mathrm{NH}_{3} \\
\left.\text { (kg year }{ }^{-1}\right)\end{array}$ & $\begin{array}{c}\mathrm{N}_{2} \mathrm{O} \\
\left(\mathrm{kg}^{2} \text { year }^{-1}\right)\end{array}$ & $\begin{array}{c}\mathrm{CH}_{4} \\
\left(\mathrm{~kg} \mathrm{year}^{-1}\right)\end{array}$ & $\begin{array}{c}\mathrm{CO}_{2} \\
\left(\mathrm{~kg}^{2} \text { year }^{-1}\right)\end{array}$ \\
\hline $\mathrm{Al}$ & 16,735 & 627 & 26,275 & 16,150 & 13,558 & 1,007 & 16,460 & $-525,710$ \\
\hline $\mathrm{A} 2$ & 14,560 & 458 & 22,516 & 12,365 & 11,659 & 824 & 13,221 & $-376,130$ \\
\hline A3 & 21,319 & 515 & 32,100 & 15,460 & 17,047 & 1,166 & 15,864 & $-321,080$ \\
\hline A4 & 32,081 & 1,400 & 1,879 & 2,675 & 30,670 & 1,814 & 3,533 & $-214,531$ \\
\hline A5 & 8,578 & 228 & 13,031 & 9,309 & 6,901 & 483 & 6,398 & $-123,865$ \\
\hline $\mathrm{A} 6$ & 28,636 & 529 & 47,462 & 24,528 & 22,466 & 1,436 & 23,581 & $-483,113$ \\
\hline $\mathrm{A} 7$ & 1,817 & 25 & 2,174 & 3,549 & 1,405 & 84 & 1,162 & $-23,095$ \\
\hline A8 & 14,390 & 222 & 22,254 & 13,288 & 11,165 & 682 & 11,187 & $-236,864$ \\
\hline A9 & 9,335 & 3 & 25,699 & 6,930 & 7,829 & 371 & 10,890 & $-125,491$ \\
\hline $\mathrm{A} 10$ & 23,336 & 6 & 68,433 & 15,828 & 19,572 & 925 & 28,997 & $-369,624$ \\
\hline All & 12,002 & 3 & 35,909 & 9,064 & 10,065 & 477 & 15,216 & $-179,273$ \\
\hline $\mathrm{A} 12$ & 32,296 & 554 & 50,499 & 22,633 & 25,235 & 1,578 & 25,309 & $-539,228$ \\
\hline total & 215,085 & 4,571 & 348,231 & 151,780 & 177,572 & 10,848 & 171,817 & $-3,518,004$ \\
\hline
\end{tabular}

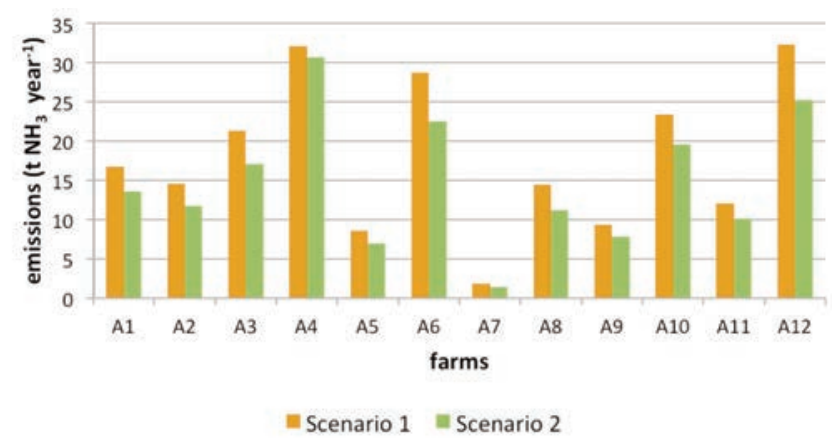

Figure 1. Comparison of the ammonia emission of the farms for the two management systems considered.

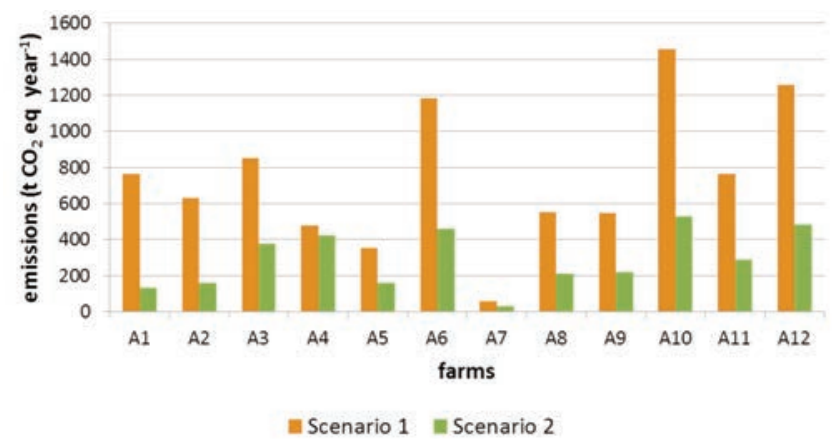

Figure 2. Comparison of the emission of $\mathrm{CO}_{2}$ equivalents for each farm for the two management systems considered 
storage has a limited production of methane.

The reduction of GHGs obtained demonstrate how this collective management systems might be sustainable despite the higher emissions due to transportation. This operation should be carefully considered as it can contribute significantly to the emissions. In the case study considered, the $\mathrm{CO}_{2}$ emissions in scenario 2 are almost twice than in scenario 1 as most of the slurry is transported with slurry tankers. The balance without considering the $\mathrm{CO}_{2}$ saved by renewable energy production is however positive, also if at lower level (18\% reduction) due to the general decrease of methane emissions.

A further evaluation of the effect of the introduction of the collective management system can be obtained from the two indicators reported in Figure 3. The first expresses the nitrogen losses to air compared to the nitrogen excreted by animal. The value of scenario 1 (55\%) is reduced of $18 \%$ in scenario 2 , confirming the benefit in terms of acidification effect and eutrophication potential.

The second one refers to nitrogen load and indicates the average amount of nitrogen applied to each hectare of land (arable or grassland). The assessment in this case should be carried out considering two aspects: the nutrient balance and regulation. The crop requirement in the area, considering the nitrogen efficiency, has an average of more than $500 \mathrm{~kg}$ of nitrogen per hectare due to the intensive cropping system, but the area has been classified as vulnerable and therefore a limit of $170 \mathrm{~kg}$ of nitrogen from animal should be considered. The nutrient removal treatment allows a reduction of $50 \%$ of the total nitrogen. Although this resulted in a nitrogen load not jet completely under the limits, it can be considered as an effective reduction of the potential release of nitrates in the waters and of the eutrophication effect. In fact considering an average nitrogen efficiency of $50 \%$ the introduction of the collective treatment plant can reduce the nitrogen release after incorporation from $215 \mathrm{~kg} \mathrm{ha}^{-1}$ to $108 \mathrm{~kg} \mathrm{ha}^{-1}$.

\section{Conclusions}

The methodology defined in the framework of the MANEV project was effective to assess the environmental impact of different manure management systems. The case study used has highlighted how a collective treatment system might be effective in the reduction of emissions to air and potential nitrogen pollution of surface and ground waters. The com-

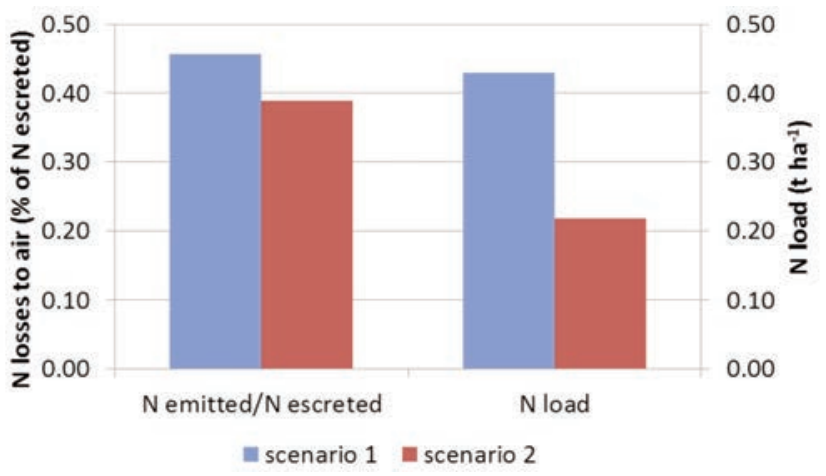

Figure 3. Nitrogen losses to air (ammonia, nitrous oxide) referred to total nitrogen excreted and total nitrogen load to the available land for the two management systems. bination of anaerobic digestion and nitrogen removal treatment has demonstrated to be sustainable also from the environmental point of view also if the benefits of renewable energy production are not considered. The reduction of emissions related to methane can compensate the increase in $\mathrm{CO}_{2}$ emissions for the transport of manure from the livestock farms to the treatment plant and vice versa. The removal treatment can reduce the nitrogen load to land at acceptable values. Although the economic assessment was outside the aim of this work, it can be considered how the possibility to have an income selling electric energy can compensate the cost of the nutrient removal treatment, making this solution sustainable also from the economic point of view. Further benefits derives from the reduction of odors and the production of a stabilized effluent that can be used as fertilizer more efficiently, with a possible reduction of mineral fertilizers and the consequent further economic and environmental benefits. Although the methodology used proved to be adequate for the assessment, it should be pointed out that there are some aspects, like the emissions from the different treatments, that will benefit of further studies in order to better consider the possible effect of different options on the emissions to air.

\section{References}

Brown S., Kruger C., Subler, S. 2008. Greenhouse Gas Balance for Composting Operations. J. Environ. Qual. 37: 1396-1410.

Burton C.H., Turner C. 2003. Manure Management - Treatment Strategies for Sustainable Agriculture (second edition). Silsoe Research Institute.

De Vries, M., de Boer, I.J.M., 2010. Comparing environmental impacts for livestock products: a review of LCA. Livest Sci.128: 1-11.

EMEP/EEA. 2009. 2009 air pollutant emission inventory guidebook. European Environment Agency.

Hansen M.N., Henriksen K., Sommer S.G. 2006. Observations of production and emission of greenhouse gases and ammonia during storage of solids separated from pig slurry: Effects of covering. Atmos. Environ. 40: 4172-4181.

IPCC 2006, 2006 IPCC Guidelines for National Greenhouse Gas Inventories, Prepared by the National Greenhouse Gas Inventories Programme, Eggleston H.S., Buendia L., Miwa K., Ngara T. and Tanabe K. (eds). Published: IGES, Japan.

Lague C., Landry H., Roberge M. 2005. Engineering of land application systems for livestock manure: A review. Can. Biosyst. Eng. 72: 9-16.

Loyon L., Guiziou F., Béline F., Peu P. 2006. Gaseous emissions (NH3, N20, CH4, CO2) during pig slurry biological aerobic treatment and treatment by-product storages. International Congress Series 1293 299-302.

Petersen S.O., Sommer S.G., Béline F., Burton C., Dach J., Dourmad J.Y., Leip A., Misselbrook T., Nicholson F., Poulsen H.D., Provolo G., Sørensen P., Vinnerås B., Weiske A., Bernal M.-P., Böhm R., Juhász C., Mihelic R. 2007. Recycling of livestock manure in a whole-farm perspective. Livest. Sci.112: 180-191.

Rigolot C., Espagnol S., Pomar C., Dourmad J. 2010. Modelling of manure production by pigs and $\mathrm{NH} 3, \mathrm{~N} 2 \mathrm{O}$ and $\mathrm{CH} 4$ emissions. part I: Animal excretion and enteric $\mathrm{CH} 4$, effect of feeding and performance. Animal. 4(8):1401-12.

Sommer S.G., Hansen M.N., Søgaard H.T. 2004. Infiltration of Slurry and Ammonia Volatilisation. Biosystems Eng. 88, 359-367. 